\title{
Seismic P-wave tomography in eastern Tibet: Formation of the rifts
}

\author{
ZHANG Heng ${ }^{*}$, ZHAO JunMeng \& XU Qiang \\ Key Laboratory of Continental Collision and Plateau Uplift, Institute of Tibetan Plateau Research, Chinese Academy of Sciences, Beijing 100085, \\ China
}

Received March 23, 2011; accepted May 17, 2011

\begin{abstract}
For better studying the relationship between the rifts and deep structure, a detailed P-wave velocity structure under eastern Tibet has been modeled using 4767 arrival times from 169 teleseismic events recorded by 51 portable stations. In horizontal slices through the model, a prominent low-velocity anomaly was detected under the rifts from the surface to a depth of $\sim 250 \mathrm{~km}$; this extends to a depth of $\sim 400 \mathrm{~km}$ in the vertical slice. This low-velocity anomaly is interpreted as an upper mantle upwelling. The observations made provide seismic evidence for the formation of north-south trending rifts. East of the low-velocity anomaly, a clear high-velocity anomaly is found between depths of 40 and $200 \mathrm{~km}$. Due to its shallow depth, we suggest that it consists of materials from an ancient continental closure rather than the Indian Plate. From depths of 250 to $400 \mathrm{~km}$, a high-velocity anomaly appears to the south of the Jiali Fault. This anomaly may correspond to the northern edge of the Indian Plate that detached from the surface under the Himalayan block. We suggest that the Indian Plate underthrusts no further than the Jiali Fault in eastern Tibet.
\end{abstract}

tomography, upper mantle upwelling, Indian plate subduction, north-south trending rifts, Tibetan Plateau

Citation: Zhang H, Zhao J M, Xu Q. Seismic P-wave tomography in eastern Tibet: Formation of the rifts. Chinese Sci Bull, 2011, 56: 2450-2455, doi: $10.1007 / \mathrm{s} 11434-011-4577-\mathrm{x}$

The Tibetan Plateau is the world's highest altitude area and a very important region for the geosciences. Since the plateau was formed by the collision of the Indian and Eurasian plates about $50 \mathrm{Ma}$ ago [1] and the subsequent postcollisional intra-continental deformation, strong structural distortion, lithospheric thickening, uplift of the plateau and development of the Himalayan mountains has occurred in this area. Although the Indus-Tsangpo, Bangong-Nujiang and Jinsha River sutures provide some evidence of Tethyan evolution, the precise relationships between the north-south trending structures of southern Tibet and the deep structure of the region are still not clear. Are they grabens [2] or deep fractures? Undoubtedly, these north-south trending structures are the most prominent surface feature in southern Tibet, but their formation mechanism and their relationships with shallow and deep structure [3] are not obvious. Resolving these problems will provide a way to better study

*Corresponding author (email: zhangheng415@163.com) the formation and evolution of the Tibetan Plateau.

To study the uplift mechanism of the Tibetan Plateau, international exploration projects such as the INDEPTH, Hi-CLIMB and ANTILOPE projects have been undertaken. These projects have provided extensive seismic data sets that can be used to investigate deep structure in this area [4-7].

In the last 20 years, much seismic research has been carried out in the Tibetan Plateau facilitated by the rapid development of seismometer technology. Surface wave investigations suggest that the entire plateau is underlain by a relatively cold lithospheric mantle [8]. Applications of travel time techniques, Zhou [9] have shown that the Indian Plate underthrusts the whole plateau. Other research has found that relatively low $\mathrm{S}$-wave velocities occur in the upper mantle of central and northern Tibet [10,11]. The work of Chen [12] supports the existence of strong radial anisotropy in most of Tibet because of the subduction of the Indian Plate under the Eurasian Plate. Using reflection seis- 
mology, Zhang $[13,14]$ detected that the thickness of crust exhibits an east-west trending change at around $31.5^{\circ} \mathrm{N}$, but there is no obvious variation at $29^{\circ} \mathrm{N}$. Moreover, he considered that the angle of the Indian Plate varies from high to low while subducting.

These seismology projects were mostly established in southern and central Tibet; less investigation has occurred in eastern Tibet. Additionally, most seismometer deployments have trended north-south, which results in arrays that are not optimally oriented for travel time tomography investigations. In this study, a 3-D P-wave velocity structure model for the crust and upper mantle of southeastern Tibet is constructed using travel time data from 51 portable stations of the Namche Barwa Broadband Seismic Network. The result displays the relationship between deep structure and the rifts of southeastern Tibet, and reveals that the Indian Plate underthrusts no further than the Jiali Fault in this area.

\section{Data and methods}

In this study, $4767 \mathrm{P}$-wave arrival times were picked from original seismograms recorded by the densely distributed portable seismometers of the Namche Barwa Broadband Seismic Network, during 2003 and 2004 (Figure 1). The picking accuracy is estimated to be 0.2 to $0.4 \mathrm{~s}$. To ensure the accuracy of the tomographic result, several rules have been considered in selecting data: (1) the magnitude is restricted to M5.5 or greater; (2) each event that includes more than 10 available records is taken into account; and (3) all events within an epicentral distance range of $30^{\circ}-90^{\circ}$ are used.

The hypocenter information was provided by the United States Geological Survey and the layout of events used in this study is shown in Figure 2. We can see that most earthquakes used in this study occurred in the eastern part of the region and only a few events were located in the western part; this is further revealed in the ray distribution (Figure 3).

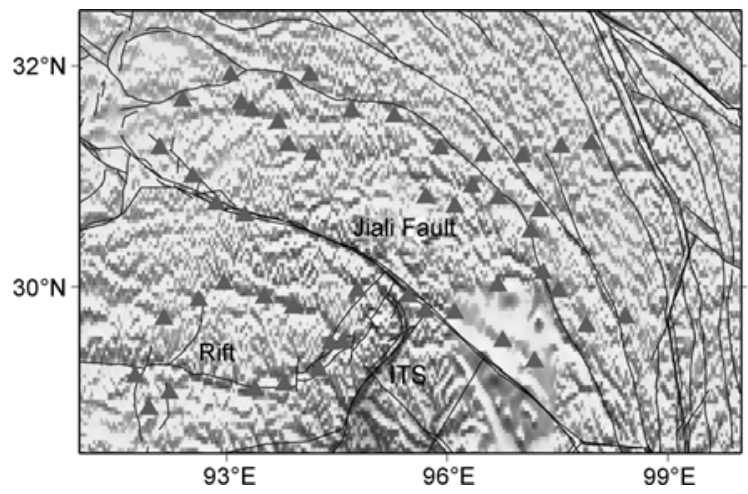

Figure 1 Map of the study region on the Tibetan Plateau. ITS denotes the Indus-Tsangpo suture; The triangles show the locations of the portable seismometers deployed in the study area. Insert map indicates the location of the study area.

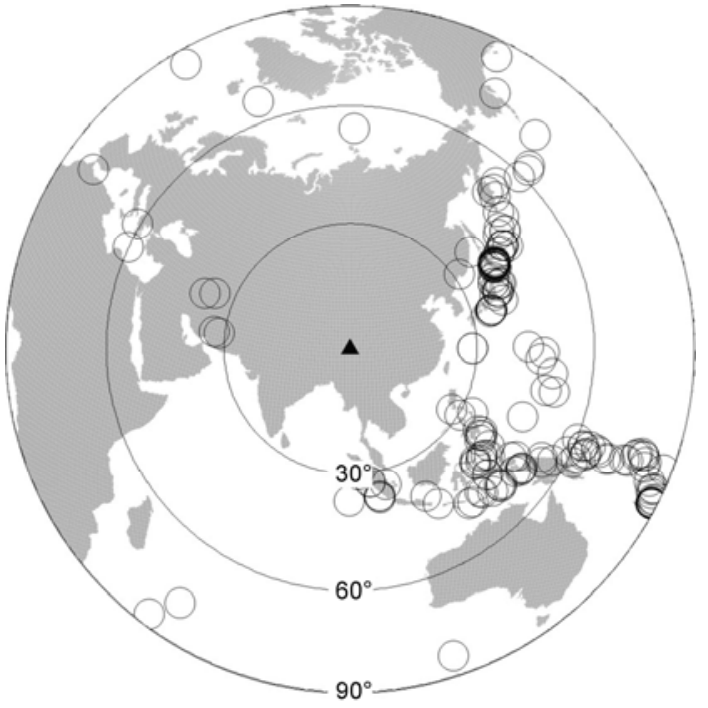

Figure 2 Distribution of 169 teleseismic events (hollow circles) used in the study. The solid triangle corresponds to the center of the study area.

Although the rays on the eastern side intersect more than those on the western side, there are enough intersects in most parts of the study area.

In the tomographic method, travel time residuals, which are derived by subtracting theoretical travel times from observed travel times, are adopted in the inversion. Theoretical travel times were calculated by applying the IASP91 model [15] and the observed travel times are derived by subtracting the origin time from the observed arrival time. Absolute residuals are often used in regional and local travel time tomography. However, because all the ray paths are included in the model, the relocation of events is very important. By contrast, teleseismic tomography can neglect the process of relocation by adopting relative residuals, which are obtained by subtracting each event's mean residual from its absolute residuals.

We know that the Tibetan crust is very different from other regions in its thickness and lateral heterogeneity. To remove the effect of this special crust, an accurate crust correction [16] was performed.

After several checkerboard tests with different grid generations, the study area has been parameterized with an optimal grid mesh of $0.5^{\circ} \times 0.5^{\circ}$ laterally and 30 to $50 \mathrm{~km}$ vertically. The $3-\mathrm{D}$ ray tracing technique can calculate ray paths efficiently and accurately. When the model contains structurally-complex velocity discontinuities, it is also powerful [17]. After ray tracing, the LSQR algorithm [18] with damping and smoothing parameters [19] was applied to invert the large and sparse observation matrix.

\section{Results}

A checkerboard test [20] has been conducted to measure the accuracy of the inversion results (Figure 4). In the checker- 

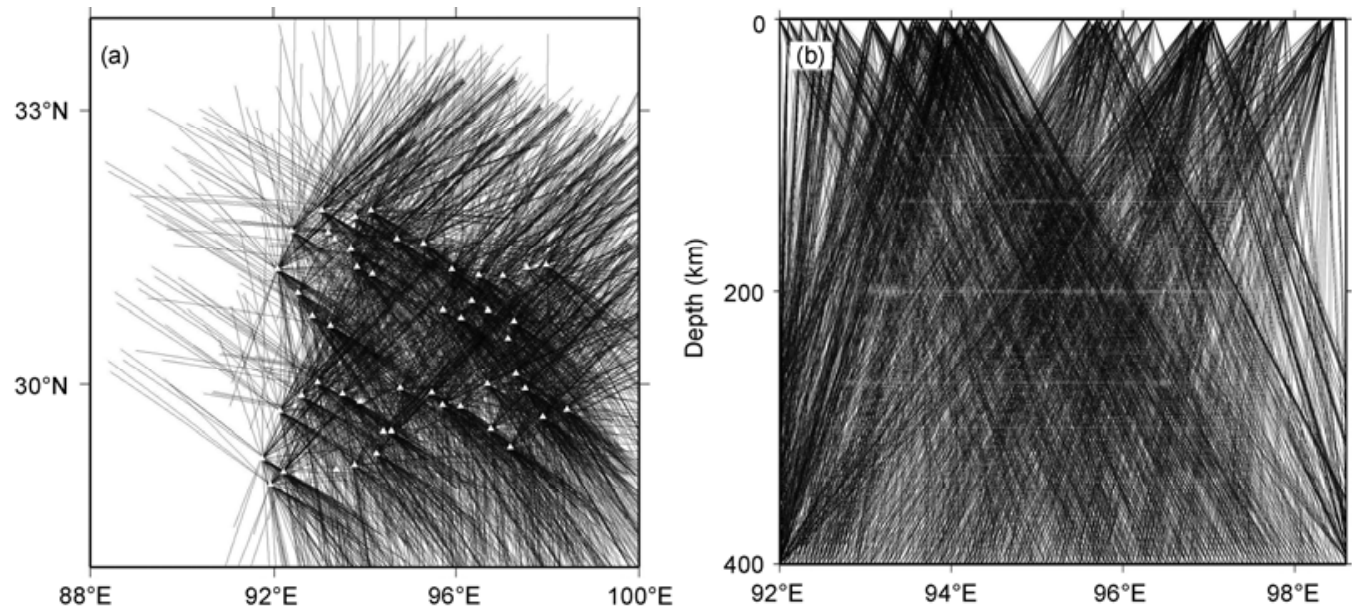

Figure 3 Distribution of the 4767 rays used in this study in plain view (a) and vertical cross-section (b).
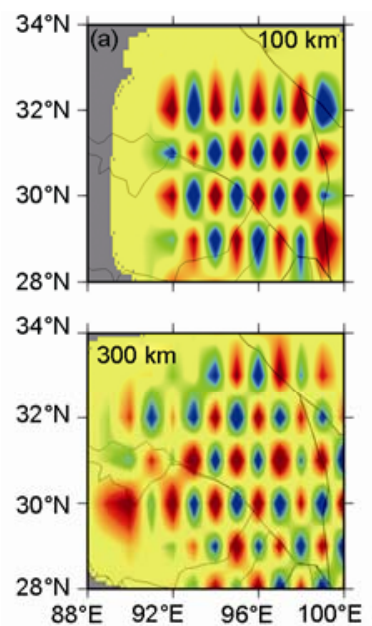

$88^{\circ} \mathrm{E} \quad 92^{\circ} \mathrm{E} \quad 96^{\circ} \mathrm{E} \quad 100^{\circ} \mathrm{E} \quad 88^{\circ} \mathrm{E} \quad 92^{\circ} \mathrm{E} \quad 96^{\circ} \mathrm{E} \quad 100^{\circ} \mathrm{E}$
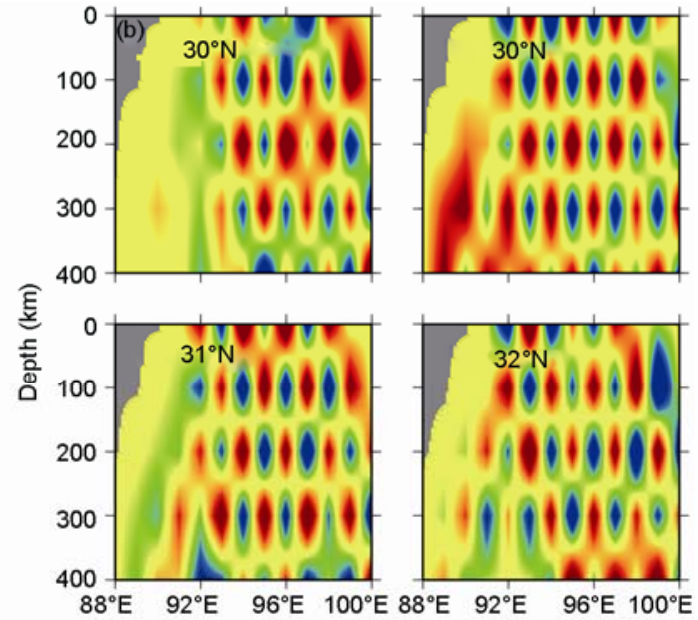

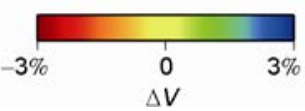

Figure 4 Checkerboard test. Red and blue denote low- and high-velocity perturbations, respectively. The velocity perturbation scale is show in the bottom.

board image, we can see that the resolution is good in both plan (Figure 4(a)) and vertical (Figure 4(b)) sections, even with apparent "smearing" at a depth of about $400 \mathrm{~km}$ due to the bottom of the model.

A horizontal slice through the inverted results beneath southeastern Tibet is shown in Figure 5. Between depths of 40 and $70 \mathrm{~km}$, the velocity anomaly shows a prominent east-west distribution. The position of the strong lowvelocity anomaly is related to the rifts on the surface, and their orientations are almost the same (i.e. trending north-south). At a depth of $100 \mathrm{~km}$, even though the east-west tendency is still obvious, the amplitude of the perturbation reduces. Between the depths of 150 and 200 $\mathrm{km}$, the tendency of the velocity perturbation varies from east-west to north-south. A high-velocity anomaly dominates south of Jiali Fault, whereas a low-velocity anomaly dominates in the north. From a depth of $250 \mathrm{~km}$ to the bottom, the north-south trending velocity anomaly distribution, which is separated by the Jiali Fault, becomes clearer; however, a high-velocity anomaly dominates to the south of Jiali Fault whereas low velocities appear in the north. Note that although the resolution at a depth of $400 \mathrm{~km}$ is poor, the central part of the model is still clear at this depth.

A vertical slice taken at $30^{\circ} \mathrm{N}$ (Figure 6) was chosen to detect the east-west trending variation beneath southeastern Tibet due to its better resolution (Figure 4). At around $92^{\circ} \mathrm{E}$, a high-velocity anomaly exists between depths of 200 and $400 \mathrm{~km}$. Also, a very strong low-velocity structure extends from the surface to a depth of $300 \mathrm{~km}$, manifested as a low-velocity anomaly shaped like a tilted pillar. Above this low-velocity structure, obvious high-velocity materials exist. 

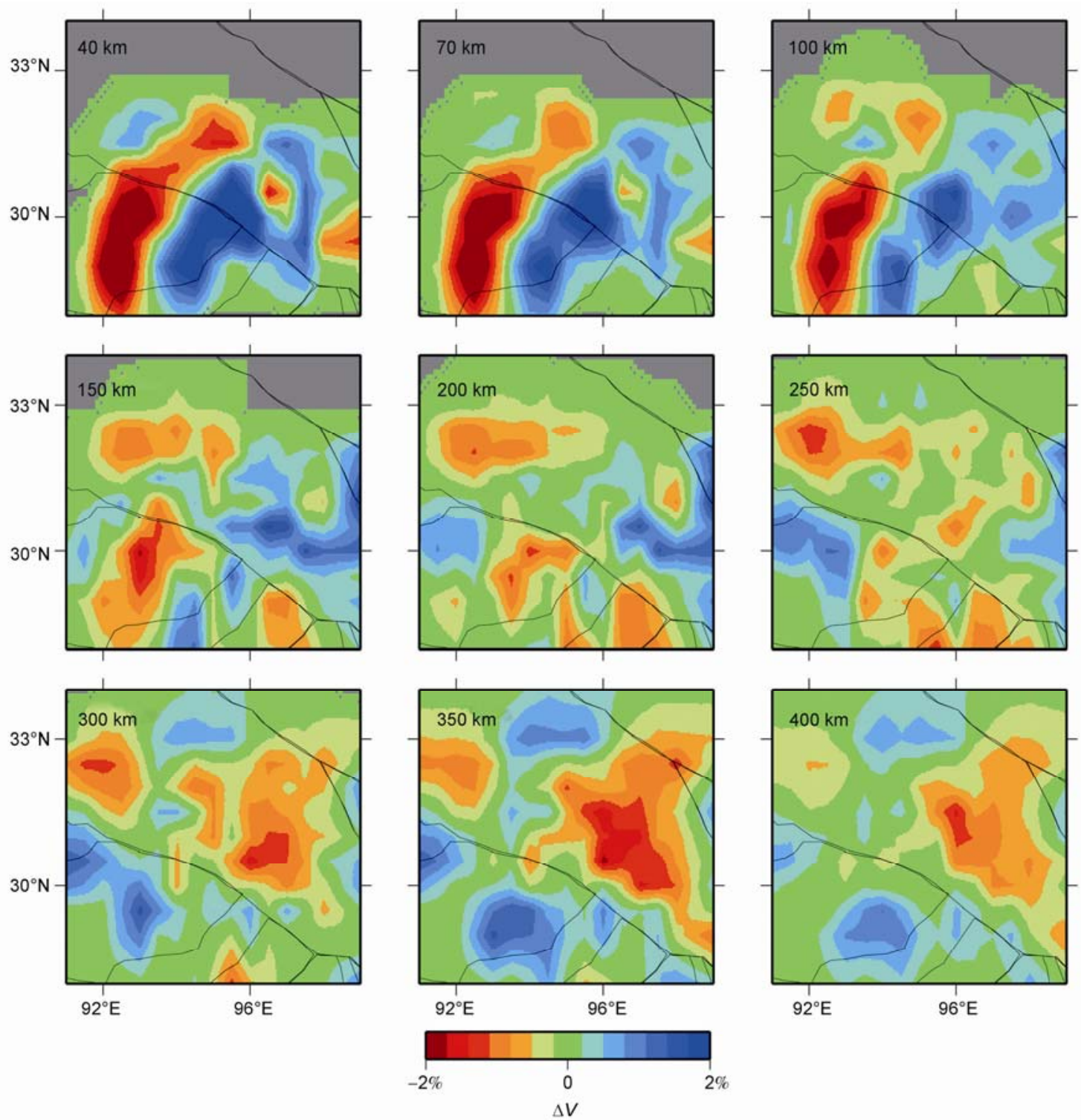

Figure 5 Plan slices of P-wave velocity beneath the study area. Red and blue denote low- and high-velocity perturbations, respectively. The perturbation scale is shown at the bottom.

\section{Discussion}

Our results at shallow depths (40-70 km, Figure 5) are similar to some earlier geophysical work in the area. The Pn wave tomography [21] showed a clear low-velocity zone exists around $91^{\circ} \mathrm{E}$. Regional tomographic results for China and surrounding regions [22] also show this low-velocity zone in the same position. These two results did not use the data from Namche Barwa, but they both found the low-velocity anomaly at almost the same position. Global tomographic imaging [23], which includes the Nameche Barwa dataset, shows a low-velocity zone extending from the surface to a depth of about $310 \mathrm{~km}$. A surface wave study [24,25] also shows this phenomenon. In addition, a prominent high-velocity anomaly is detected to the east of the obvious low-velocity anomaly. Using travel time tomo- graphic techniques in the same region, Li et al. [26] limited the underthrust of the Indian Plate to no further than $30^{\circ} \mathrm{N}$. Furthermore, he pointed out that the underthrusting distance becomes shorter from west to east. Using the same data, Ren et al. [27] also detected this high-velocity anomaly and proposed that it represents the Indian Plate.

On the other hand, the high-velocity anomaly seen in our results at shallow depths (above $70 \mathrm{~km}$ ) contrasts with a low-velocity anomaly seen in some shallow geophysical work in the same region. For example, Makovsky et al. [28] proposed concentrations of free aqueous-fluid in the Tibetan middle crust based on controlled-source seismic data. Using Rayleigh wave tomography and the same dataset as this study, Fu et al. [29] also did not find the high-velocity anomaly at shallower depths (above $40 \mathrm{~km}$ ). Such interpretations are found in results from magnetotelluric [30,31] and 


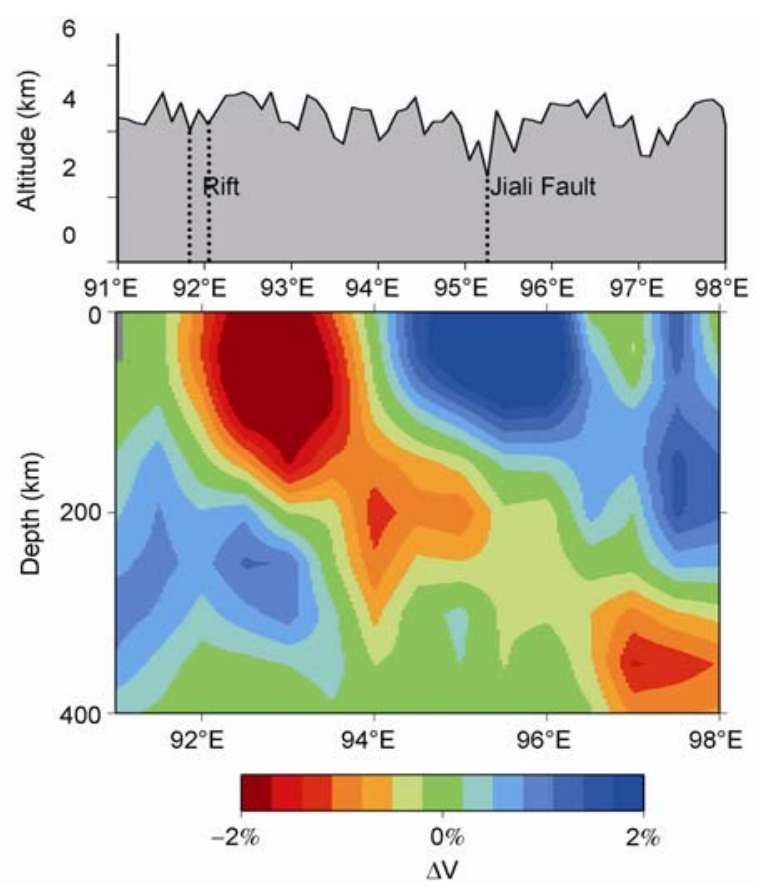

Figure 6 P-wave velocity slice along $30^{\circ} \mathrm{N}$.

reflection seismic [13] surveys. Using a Rayleigh and Love wave tomographic technique, but with different data, Chen et al. [32] detected this strong low-velocity anomaly and agreed that fluid flow in the middle crust may exist here.

At depths between 70 and $200 \mathrm{~km}$, our high-velocity result is consistent with $\mathrm{Fu}$ et al. [29]. However, both $\mathrm{Fu}$ et al. [29] and Kumar et al. [33] have suggested that this anomaly is the Asian Plate. Comparing our results with those of other earlier studies, there is no such high-velocity anomaly existing around $98^{\circ} \mathrm{E}$ [26]. In the east of southeastern Tibet, in the vicinity of the Longmen Fault, travel time tomography [34,35] did not support the subduction of the Asian lithosphere directly to eastern Tibet. Besides these, there are no other obvious high-velocity anomalies to the west of the low-velocity zone [22,26,36]. Thus we suggest that this high-velocity anomaly is not caused by Indian Plate subduction, but rather due to materials sinking during continental closure, which are then taken to the surface by mantle material upwelling. From $200 \mathrm{~km}$ to the bottom of the model, a high-velocity anomaly primarily appears to the south of the Jiali Fault and a low-velocity anomaly dominates to the north. Because of this, we suggest that the Indian Plate underthrusts no further than the Jiali Fault and then breaks off under the Himalayan block. In addition to this feature, although we cannot be certain that the Jiali Fault is the distinct velocity boundary above $100 \mathrm{~km}$ depth, it becomes clearer between depths of 150 and $400 \mathrm{~km}$. The particular reason for this phenomenon calls for further study.

By applying the receiver function method, Singh et al. [37] suggested that the strong low-velocity anomaly is caused by the delamination of the Indian lithosphere into the transition zone (beneath the $410 \mathrm{~km}$ discontinuity). The main reason for the formation of rifts in southeastern Tibet is mantle material upwelling as we discussed in this study. Moreover, the pattern of upwelling is not vertical, but tilted, similar to the deflected upwelling that has been detected under Iceland, Hawaii, and the Baikal region [36]. The range of the rifting in southeastern Tibet is relatively small compared with that of Baikal and lacks correlative studies, but we still prefer the interpretation of deflected upwelling due to the good resolution(Figure 4(b)), computer simulation results [38] and the value of $V_{\mathrm{p}} / V_{\mathrm{s}}$ [27].

To the west of this low-velocity zone, a high-velocity anomaly is detected between depths of 100 and $400 \mathrm{~km}$. The resolution of this region $\left(92^{\circ}\right.$ to $\left.94^{\circ} \mathrm{E}\right)$ is believable, despite boundary effects. We suggest that this high-velocity structure corresponds to the Indian Plate due to its location and comparison with previous results [5,26]. Moreover, we suggest that Indian Plate subduction induced mantle upwelling in this region.

In this study, our determination of the structure beneath the rifts in southeastern Tibet could only be made because of the location of the portable seismometers. To study the relationships further between the rifts in southeastern and southern Tibet, more portable stations will need to be established.

\section{Conclusions}

A detailed P-wave velocity structure model under eastern Tibet was built using travel times collected from portable stations in Namche Barwa. Above a depth of $100 \mathrm{~km}$, the distribution of velocities shows a clear east-west trend. From $150 \mathrm{~km}$ to the bottom of the model at $400 \mathrm{~km}$, this trend varies from east-west to south-north, separated by the Jiali Fault. In southeastern Tibet, the Indian Plate underthrusts not far beyond the Jiali Fault, with a depth range of 150 to $350 \mathrm{~km}$, and breaks off beneath the Himalayan block. Low-velocity anomalies with amplitudes of $2 \%$ are revealed under the rifts at around $92^{\circ} \mathrm{E}$. This low-velocity structure extends from the surface down to a depth of $400 \mathrm{~km}$ and tilts toward the east along the $30^{\circ} \mathrm{N}$ profile. We interpreted this as upper mantle upwelling, an observation that provides seismic evidence for the formation of the north-south trending rifts. The transverse flow of mantle material induces the pattern of deflected upwelling.

The data used in this study were recorded by the Namche Barwa Broadband Seismic Network Project and the original data were downloaded from the IRIS Data Management Center. We thank Prof. Zhao Dapeng for providing his tomographic program and anonymous reviewers who provided constructive suggestions to improve this paper. This work was supported by the National Basic Research Program of China (2008CB425704 and 2006CB202301) and the National Natural Science Foundation of China (0930317). 
1 Yin A, Harrison T M. Geologic evolution of the Himalayan-Tibetan orogen. Annu Rev Earth Planet Sci, 2000, 28: 211-280

2 Wu Z H, Zhang Y S, Hu D G, et al. Quaternary normal faulting and its danamic mechanism of the cona-nariyong co graben in southeastern Tibet (in Chinese). Quat Sci, 2008, 28: 232-242

3 Jimenez-Munt I, Platt J P. Influence of mantle dynamics on the topographic evolution of the Tibetan Plateau: Results from numerical modeling. Tectonics, 2006, 25, doi:10.1029/2006TC001963

4 Zhao J M, Yuan X H, Liu H B, et al. The boundary between the Indian and Asian tectonic plates below Tibet. Proc Natl Acad Sci USA, 2010, 107: 11229-11233

5 Tilmann F, Ni J, Team I I S. Seismic imaging of the downwelling Indian lithosphere beneath central Tibet. Science, 2003, 300: 14241427

6 Nabelek J, Hetenyi G, Vergne J, et al. Underplating in the Himalaya-Tibet Collision Zone revealed by the Hi-CLIMB experiment. Science, 2009, 325: 1371-1374

7 Su W, Wang C Y, Huang Z X. Azimuthal anisotropy of Rayleigh waves beneath the Tibetan Plateau and adjacent areas. Sci China Ser D-Earth Sci, 2008, 51: 1717-1725

8 Priestley K, Debayle E, McKenzie D, et al. Upper mantle structure of eastern Asia from multimode surface waveform tomography. J Geophys Res, 2006, 111, doi:10.1029/2005JB004082

9 Zhou H W, Murphy M A. Tornographic evidence for wholesale underthrusting of India beneath the entire Tibetan plateau. J Asian Earth Sci, 2005, 25: 445-457

10 Rapine R, Tilmann F, West M, et al. Crustal structure of northern and southern Tibet from surface wave dispersion analysis. J Geophys Res, 2003, 108, doi:10.1029/2001JB000445

11 Lebedev S, van der Hilst R D. Global upper-mantle tomography with the automated multimode inversion of surface and S-wave forms. Geophys J Int, 2008, 173: 505-518

12 Chen Y, Badal J, Zhang Z J. Radial anisotropy in the crust and upper mantle beneath the Qinghai-Tibet Plateau and surrounding regions. J Asian Earth Sci, 2009, 36: 289-302

13 Zhang Z J, Klemperer S. Crustal structure of the Tethyan Himalaya, southern Tibet: New constraints from old wide-angle seismic data. Geophys J Int, 2010, 181: 1247-1260

14 Zhang Z J, Klemperer S L. West-east variation in crustal thickness in northern Lhasa block, central Tibet, from deep seismic sounding data. J Geophys Res, 2005, 110, doi:10.1029/2004JB003139

15 Kennett B L N, Engdahl E R. Traveltimes for Global Earthquake Location and Phase Identification. Geophys J Int, 1991, 105: 429-465

16 Jiang G M, Zhao D P, Zhang G B. Crustal correction in teleseismic tomography and its application. Chin J Geophys, 2009, 52: 15081514

17 Zhao D P, Hasegawa A, Horiuchi S. Tomographic imaging of P-wave and S-wave velocity structure beneath Northeastern Japan. J Geophys Res, 1992, 97: 19909-19928

18 Paige C C, Saunders M A. Lsqr-an algorithm for sparse linearequations and sparse least-squares. ACM Trans Math Softw, 1982, 8: 43-71

19 Zhao D. Seismic structure and origin of hotspots and mantle plumes. Earth Planet Sci Lett, 2001, 192: 251-265

20 Humphreys E, Clayton R W. Adaptation of Back Projection Tomography to Seismic Travel Time Problems. J Geophys Res, 1988, 93: 1073-1085

21 Liang C T, Song X D. A low velocity belt beneath northern and east- ern Tibetan Plateau from Pn tomography. Geophys Res Lett, 2006, 33, doi:10.1029/2006GL027926

22 Huang J L, Zhao D P. High-resolution mantle tomography of China and surrounding regions. J Geophys Res, 2006, 111, doi:10.1029/ 2005 JB004066

23 Zhou H W, Murphy M A, Lin Q L. Tomographic imaging of the Tibet and surrounding region: Evidence for wholesale underthrusting of Indian slab beneath the Tibetan Plateau (in Chinese). Earth Sci Front, 2002, 9: 285-292

24 Sun R M, Zhang Z J, Teng J W, et al. Discussion on the lateral extrusion of Tibetan mass-Evidence of surface wave tomography (in Chinese). In: Zhang Z J, Gao R, Lü Q T, et al., eds. Study on the Chinese Continental Deep Structure and Geodynamics. Beijing: Science Press, 2004. 872-880

25 Zhang X M, Sun R M, Teng J W. Study on crustal, lithospheric and asthenospheric thickness beneath the Qinghai-Tibet Plateau and its adjacent areas. Chinese Sci Bull, 2007, 52: 797-804

26 Li C, Van der Hilst R D, Meltzer A S, et al. Subduction of the Indian lithosphere beneath the Tibetan Plateau and Burma. Earth Planet Sci Lett, 2008, 274: 157-168

27 Ren Y, Shen Y. Finite frequency tomography in southeastern Tibet: Evidence for the causal relationship between mantle lithosphere delamination and the north-south trending rats. J Geophys Res, 2008, 113, doi:10.1029/2008JB005615

28 Makovsky Y, Klemperer S L. Measuring the seismic properties of Tibetan bright spats: Evidence for free aqueous fluids in the Tibetan middle crust. J Geophys Res, 1999, 104: 10795-10825

29 Fu Y Y V, Li A B, Chen Y J. Crustal and upper mantle structure of southeast Tibet from Rayleigh wave tomography. J Geophys Res, 2010, 115, doi:10.1029/2009JB007160

30 Bai D H, Unsworth M J, Meju M A, et al. Crustal deformation of the eastern Tibetan plateau revealed by magnetotelluric imaging. Nat Geosci, 2010, 3: 358-362

31 Zhao G Z, Chen X B, Wang L F, et al. Evidence of crustal 'channel flow' in the eastern margin of Tibetan Plateau from MT measurements. Chinese Sci Bull, 2008, 53: 1887-1893

32 Chen Y, Badal J, Hu J F. Love and Rayleigh Wave Tomography of the Qinghai-Tibet Plateau and Surrounding Areas. Pure Appl Geophys, 2010, 167: 1171-1203

33 Kumar P, Yuan X H, Kind R, et al. Imaging the colliding Indian and Asian lithospheric plates beneath Tibet. J Geophys Res, 2006, 111, doi:10.1029/2008JB005615

34 Wei W, Sun R M, Shi Y L. P-wave tomographic images beneath southeastern Tibet: Investigating the mechanism of the 2008 Wenchuan earthquake. Sci China Ser D-Earth Sci, 2010, 53: 1252-1259

$35 \mathrm{Li} \mathrm{Z} \mathrm{W,} \mathrm{Xu} \mathrm{Y,} \mathrm{Huang} \mathrm{R} \mathrm{Q.} \mathrm{Crustal} \mathrm{P-wave} \mathrm{velocity} \mathrm{structure} \mathrm{of} \mathrm{the}$ Longmenshan region and its tectonic implications for the 2008 Wenchuan earthquake. Sci China Ser D-Earth Sci, 2011: doi: 10.1007/ s11430-011-4177-2

36 Zhao D P. Global tomographic images of mantle plumes and subducting slabs: insight into deep Earth dynamics. Phys Earth Planet Inter, 2004, 146: 3-34

37 Singh A, Kumar M R. Seismic signatures of detached lithospheric fragments in the mantle beneath eastern Himalaya and southern Tibet. Earth Planet Sci Lett, 2009, 288: 279-290

38 Steinberger B. Plumes in a convecting mantle: Models and observations for individual hotspots. J Geophys Res, 2000, 105: 1112711152

Open Access This article is distributed under the terms of the Creative Commons Attribution License which permits any use, distribution, and reproduction in any medium, provided the original author(s) and source are credited. 